\title{
Evolution and developmental diversity of tooth regeneration ${ }^{\text {th }}$
}

\author{
Abigail S. Tucker ${ }^{\mathrm{a}}$, Gareth J. Fraser ${ }^{\mathrm{b}, *}$ \\ a Department of Craniofacial Development and Stem Cell Biology, Floor 27 Guy's Tower, Guys Campus, King's College London, SE1 9RT, UK \\ b Department of Animal and Plant Sciences, Alfred Denny Building, Western Bank, University of Sheffield, S10 2TN, UK
}

\section{A R T I C L E I N F O}

\section{Article history:}

Available online 6 January 2014

\section{Keywords:}

Tooth development

Stem cells

Regeneration

Tooth replacement

Dental lamina

Vertebrate diversity

\begin{abstract}
A B S T R A C T
This review considers the diversity observed during both the development and evolution of tooth replacement throughout the vertebrates in a phylogenetic framework from basal extant chondrichthyan fish and more derived teleost fish to mammals. We illustrate the conservation of the tooth regeneration process among vertebrate clades, where tooth regeneration refers to multiple tooth successors formed de novo for each tooth position in the jaws from a common set of retained dental progenitor cells. We discuss the conserved genetic mechanisms that might be modified to promote morphological diversity in replacement dentitions. We review current research and recent progress in this field during the last decade that have promoted our understanding of tooth diversity in an evolutionary developmental context, and show how tooth replacement and dental regeneration have impacted the evolution of the tooth-jaw module in vertebrates.
\end{abstract}

\section{Contents}

1. Introduction

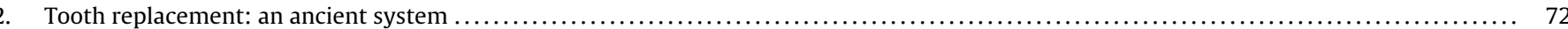

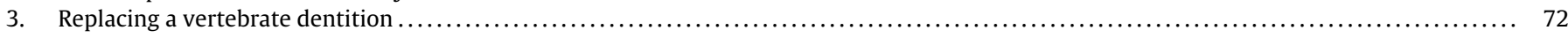

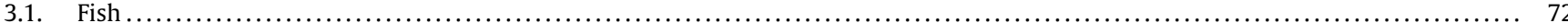

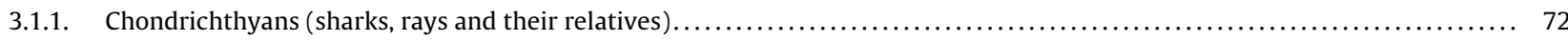

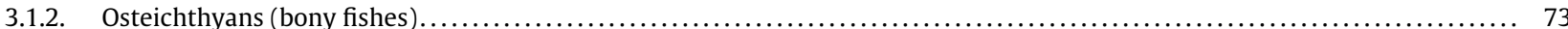

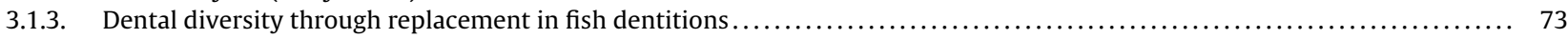

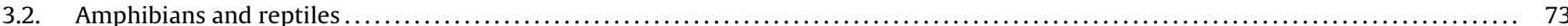

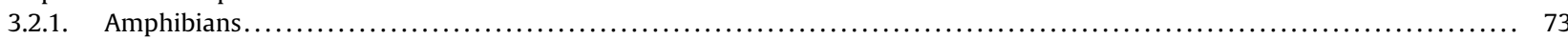

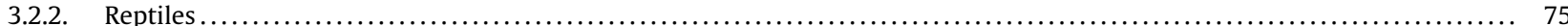

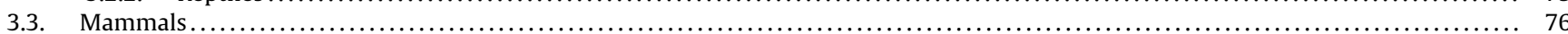

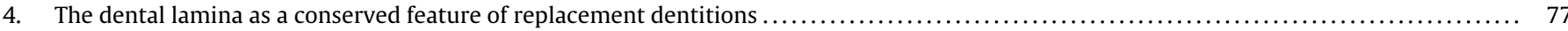

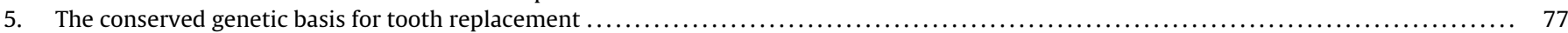

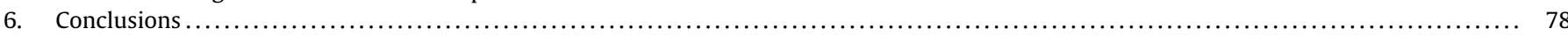

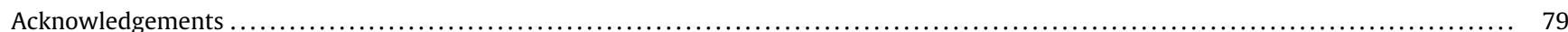

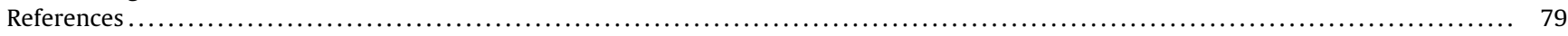

\footnotetext{
is This is an open-access article distributed under the terms of the Creative Commons Attribution License, which permits unrestricted use, distribution and reproduction in any medium, provided the original author and source are credited.

* Corresponding author. Tel.: +44114222 4317.

E-mail addresses: abigail.tucker@kcl.ac.uk(A.S.Tucker), g.fraser@sheffield.ac.uk (G.J. Fraser).
}

\section{Introduction}

Vertebrate animals show morphological diversity that is the product of change during the process of evolution based on developmental modulation; this is the basis of Evo-Devo. For a complete understanding of the dentition, evolutionary and developmental studies are essential for the appreciation of complexities that have led to changes in tooth development, form, function and regeneration. Given the diversity in form observed among vertebrates, the dentition presents an intriguing paradox; while there is great structural and developmental conservation of tooth unit 
formation, there is vast diversity of form, replacement potential and module integration, i.e. the combined system of both jaws and teeth. The dentition has remained extremely similar throughout vertebrate evolution, both in terms of the genetic basis and the structure of the unit tooth; however vertebrates have highly diverse dentitions and capacities for dental regeneration. This contradictory notion is ideal for the field of 'Evolutionary Developmental Biology'; how does a system so highly conserved as the dentition become so vastly modified to provide the diversity of dental form observed among vertebrates?

In this context we define dental regeneration as repeated and cyclical induction of tooth germs, from a set of well-maintained dental progenitor cells at each tooth position in the jaw, primed to replace each functional tooth in a one-for-one (a single replacement tooth is formed at any one time for a single tooth position) or many-for-one (where many replacement teeth are formed ahead of function for a single tooth position) capacity. This concept suggests that there are two basic strategies for tooth replacement: (1) the formation of one replacement tooth before replacing the functional tooth after which the next single replacement forms and (2) many teeth are formed in a developmental time series to replace a single functional tooth. Teeth are replaced during an animal's life in order to counter the problems of tooth wear, or tooth damage, while also providing the possibility of change to tooth morphology and complexity, which might be required during the lifetime of the animal, for example, changing diets from larval to adult forms. Not all animals replace their dentition, and as such are classed as monophyodont (single generation of functional teeth). At the opposite end of the spectrum are the polyphyodonts, which replace their teeth continuously. How the dentition is replaced has been a largely forgotten subject, partly because the standard animal models used in developmental biology are not ideal for the study of tooth replacement. The mouse, the main mammalian model for development, does not have the capacity to replace its dentition de novo. Instead of replacing whole teeth the mouse counteracts the problems of tooth wear by having continuously growing incisors, with a continuous production of enamel and dentine tissue secreting cells - a tooth renewal system [1-4]. The mouse is therefore insufficient to understand how mammals replace teeth. The chick (Gallus gallus) lacks teeth, although some reports suggest that some chick embryos (at approximately stage 27 [5]) can start the process of tooth initiation soon after which the rudimentary dental lamina is aborted [5-7]. The zebrafish (Danio rerio) is a highly derived Teleost species of the order Cypriniformes and over the past 30 years has become the top fish developmental model owing to its transparency during embryogenesis, the ease of vast embryo production and the development of genomic tools. The zebrafish has become a useful model for tooth development and manipulation [8] however the tiny teeth of zebrafish and teeth in all Cypriniformes are confined to the back of the gill arches, embedded deep within the pharyngeal cavity, with oral teeth in this order having been lost approximately 50 million years ago [9].

These issues with current developmental models have led to a recent surge in studies focused on natural tooth replacement in a variety of polyphodont and diphyodont (two sets of teeth) species [10-14]. The timing of this increase in research could not have come at a better time - now any organism is accessible as a potential model for developmental biology given our current advanced genomic, cellular and developmental technologies. Given this we have now seen an extended selection of models that are successfully being adopted to offer new insights into both the evolution and development of tooth replacement mechanisms. This review discusses this diversity of tooth replacement capabilities among vertebrates, the genetic and cellular origins of this phenomenon and the state of research in this field of dental evolutionary developmental biology.

\section{Tooth replacement: an ancient system}

The teeth have been relatively unchanged throughout the evolution of vertebrates. Their development is governed by a highly conserved network of genes. This 'dental network' controls oral epithelial and mesenchymal cells towards the production of a tooth composed for the most part of dentine and enamel-like mineralised tissues, surrounding an innervated, vascularised pulp cavity. The conservation of the tooth unit is extremely stable with the exception of those vertebrates, like the birds (Class Aves), turtles (order Testudines/Chelonii) and some mammals (including the anteaters; suborder Vermilingua) that have lost their tooth building capability and are for the most part, toothless. These toothless clades have all secondarily lost their teeth with fossil evidence showing toothed forms of most groups $[6,15]$. Interestingly, there are many vertebrates that do develop an initial and complete set of teeth that are lost and never replaced. In some groups, these first generation teeth are replaced by keratinous projections that develop in place of the teeth and act as a substitute dentition ([6] as observed in the duckbilled platypus - Ornithorhynchus anatinus), while in other animals alternative feeding devices are adopted that do not require a dentition, i.e. filter feeding mechanisms observed in baleen whales (suborder Mysticeti [6]) and some ray-finned fishes, e.g. Acipenseriformes [16].

The basal tooth condition for early vertebrates was likely polyphyodonty [17-21]. The capacity for teeth to replace themselves is a potential defining character of true teeth, and distinguishes them from dermal tooth-like elements (odontodes). Continuous tooth replacement is an ancient biological process and for this progenitor cells must be maintained. This ancient regenerative system must have utilised a population of stem cells that has been conserved for the same function throughout vertebrate evolution. Vertebrates have reduced the number of tooth sets over time with fewer teeth in the mouth at any one time, combined with a loss of tooth replacement capabilities [6]. This appears to correlate with a general shift to complex teeth, indicating a trade off between how many teeth are produced and the level of tooth shape complexity [22].

\section{Replacing a vertebrate dentition}

\subsection{Fish}

Fish can be separated into two distinct clades and for the purposes of this discussion these two clades represent (i) the bony fishes (Osteichthyes) - Actinopterygii and Sarcopterygii; and (ii) the cartilaginous fishes (Chondrichthyes) - sharks, rays and chimaeras. Most fish groups possess oral teeth that undergo continuous tooth replacement (polyphyodonty) and represent the most basal extant vertebrates, important for an evolutionary and phylogenetic context.

\subsubsection{Chondrichthyans (sharks, rays and their relatives)}

The sharks and rays (elasmobranchs) represent some of the most basal extant vertebrates. Maybe surprisingly, they have received little attention in the literature with respect to the development of their dentition. Elasmobranchs have a unique dental system that takes advantage of a conveyor-belt type continuous dentition (polyphyodonty) with multiple families of developing teeth produced ahead of function. Elasmobranchs possess a basal dental system where, underlying the functional teeth, are a set of replacements made in advance, and ahead of function.

The teeth of elemobranchs are adapted to utilise a many-for-one replacement system to great effect, creating an extremely efficient food-processing tool, which has facilitated the evolution of these 
apex predators. Damaged or lost teeth do not present an issue in this system as new replacement teeth appear rapidly in elasmobranch species, e.g. every 9-12 days in the adult Leopard shark (Triakis semifasciata) [23]. This replacement rate appears more rapid during ontogeny and varies among species [24], depending on age, diet and seasonal shifts [23].

Tooth initiation starts with the odontogenic band, an arc of thickened epithelial cells that line the jaw margin found in all vertebrates and labelled by genes such as Pitx2 and Shh [13]. The collaboration of these two genes may infer tooth competence [25-28]. In sharks, the thickening or proliferation of the cells in the odontogenic band continues posto-dorsally coincident with an in-pushing of the basal layer into the underlying and condensed mesenchyme [29-31] (Fig. 1). This creates a fold of epithelium that is continuous along the jaw, known as the dental lamina [30-32]. The oro-lingual extent of the dental lamina is where new tooth replacements are formed (Fig. 1) - a group of cells at the deepest part of the dental lamina. The dental lamina in sharks is a jaw-length, epithelial structure that consists of regions containing tooth families (in developmental series) and inter-tooth lamina, devoid of teeth as spacer units.

The ability of the epithelial dental lamina to invaginate within the lingual aspect of the jaws has governed the evolution of this many-for-one system of functional teeth followed by a developing series of replacements. Thus the teeth are not restricted for attachment onto a 'bone' and furthermore the replacement teeth do not develop within bony cavities. Instead the teeth are produced in great numbers and develop within the deep soft tissue of the dental lamina that in most species resides within a cup-like space formed next to the developing cartilage (Fig. 1). The teeth become attached during the eruption phase of tooth development via connective tissues that attach the teeth to the cartilages of the upper and lower jaws.

\subsubsection{Osteichthyans (bony fishes)}

The teeth of teleosts generally undergo a 'one-for-one' system of tooth replacement (Fig. 2), meaning that each tooth position is replaced with another single tooth in a cyclical manner throughout life [33,34]. The rainbow trout (Oncorhynchus mykiss; Salmonidae) is a relatively basal member of the teleosts and undergoes tooth replacement without a classic dental lamina [33]. Instead the dental epithelial cells (outer dental epithelium) that surround the developing tooth during development are in-turn thickened to produce extremely superficial replacements. In the cichlids the first generation teeth and the specific cells associated with their development are integral to the initiation of the proliferating dental lamina. Cichlids have an intraosseous replacement system, where new tooth replacements develop within cavities underlying each functional tooth position (Fig. 2). Cichlids develop a dental lamina (successional lamina), similar to the zebrafish successional lamina and proliferates from surface (oral) epithelium at the junction between a taste-territory and the cells associated with the dental epithelial stream that invaginates into small openings in the bony matrix (gubernacular canals) [11]. This stream of epithelial cells, forming a successional lamina, effectively delivers the dental epithelial cells necessary for the generation of the next tooth. The multigenerational production of tooth replacements in cichlids highlights that each tooth has the capacity for autonomous replacement in cavities directly underlying the functional tooth [11], ensuring that the replacing tooth can occupy the exact position of its predecessor (Fig. 2). The rate of tooth replacement in cichlids depends on the age and species, with adult cichlids able to replace their teeth every 30-100 days [35]. Cichlids, as in most of the teleosts studied, replace each of their teeth via the one-for-one system of tooth replacement, however there are exceptions that show novelty in teleost dental evolution with alternative replacement systems, i.e. many-for-one tooth replacement.

\subsubsection{Dental diversity through replacement in fish dentitions}

The diversity of teleost fishes is well reflected in their diverse dental morphotypes. The modification of the dentition in fishes is aided in part by the capacity for continuous tooth replacement. For example in the cichlids from Lake Malawi this dental modification is extreme with a shift in tooth morphology from the basic conical unicuspid-type in the first generation to the elaborate selection of multicuspid dental forms observed in adults only after multiple rounds of tooth replacement $[11,36]$ (Fig. 2). This generational transition of tooth shape in Malawi cichlids demonstrates that dental diversity is the result of continuous dental regeneration - the cyclical propagation of ectodermally derived cells kick-starts new tooth formation and modulation of tooth type.

The shift from an embryonic dentition to a more complex and elaborate dentition, in terms of shape and organisation, seems to be a common feature among teleost fishes with continuous tooth replacements. In one derived family of teleosts, the pufferfishes (Tetraodontids; Fig. 3), this developmental transition of tooth generation has produced an adult dentition that is suggestive of ontogenetic morphological novelty [37]. Adult pufferfishes have a beak-like dentition, quite unique and independent from all other dentitions, constructed from only four tooth positions. The development of the adult beak morphology is only possible due to the ability to regenerate the dentition in a many-for-one system (many replacement teeth formed ahead of function for one tooth position) - thus this is an example of continuous tooth regeneration resulting in ontogenetic dental novelty. The first generation dentition of the pufferfish is similar as in other teleosts without any initial signs of an extraordinary morphology (Fig. 3). Most of the tooth positions occupied by the first generation teeth are lost and only the four most medial teeth are replaced and it is this transition between the first and second generation dentition that marks the first indication of extreme modification towards a beak. Labial epithelial cells associated both with the surface oral epithelium and cells of the successional lamina form an invaginated complex of cells (Fig. 3A). These cells proliferate and invade the bony cavity to form the stacked bands of dentine that produce the characteristic beak (Fig. 3). This suggests that developmental tinkering does not end during early embryogenesis and that later in ontogeny a system with self-regulated regeneration is capable of later stage modifications that can lead to alternative adult condition.

\subsection{Amphibians and reptiles}

\subsubsection{Amphibians}

Extant amphibians include frogs, salmanders and caecilians, divided into the Gymnophiona (caecilians), Anura (frogs and toads) and Caudata (salamanders and newts). Amphibians, like many fish, have polyphyodont dentitions but the teeth are restricted to the oral cavity. In most species the first generation larval teeth are simple and monocuspid, while the replacement teeth are larger and bicuspid [38], although in a few species the adult teeth are also monocuspid (e.g. Xenopus laevis) [39]. This highlights again how replacement allows for the generation of teeth of completely new morphologies, allowing for changes in lifestyle and diet. As observed in fish, amphibians have a diverse selection of tooth replacement modes, utilising for the most part a one-for-one system. However, depending on the rate of tooth replacement, more than one replacement tooth can be in the process of developing at a given time. This suggests that the timing of tooth replacement development may alter whether a species has a one-for-one or a many-for-one continuous replacement system. 

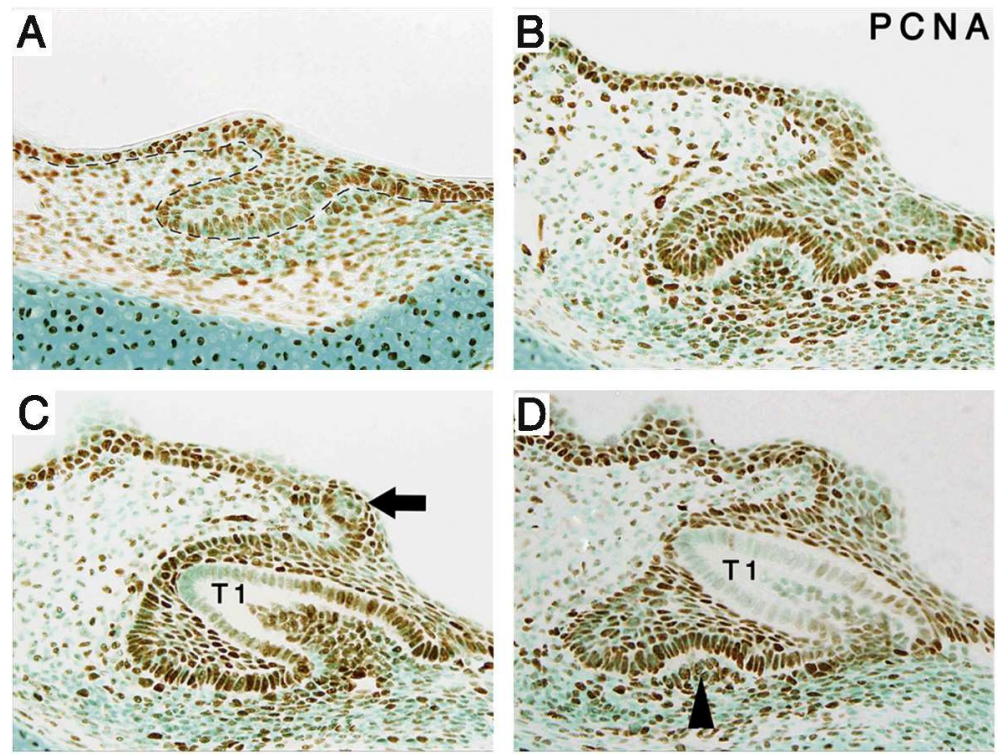

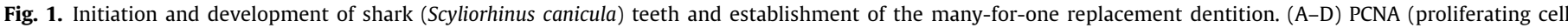

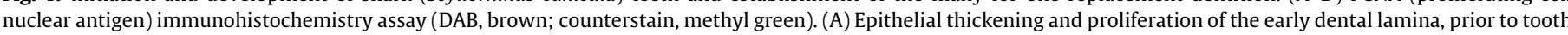

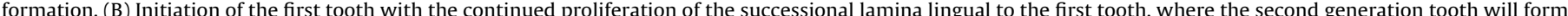

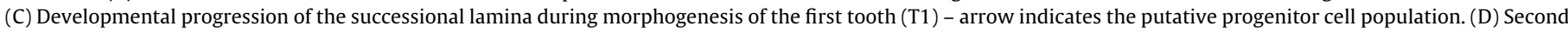
tooth initiation from the thickening of the distal dental lamina (arrowhead; successional lamina).
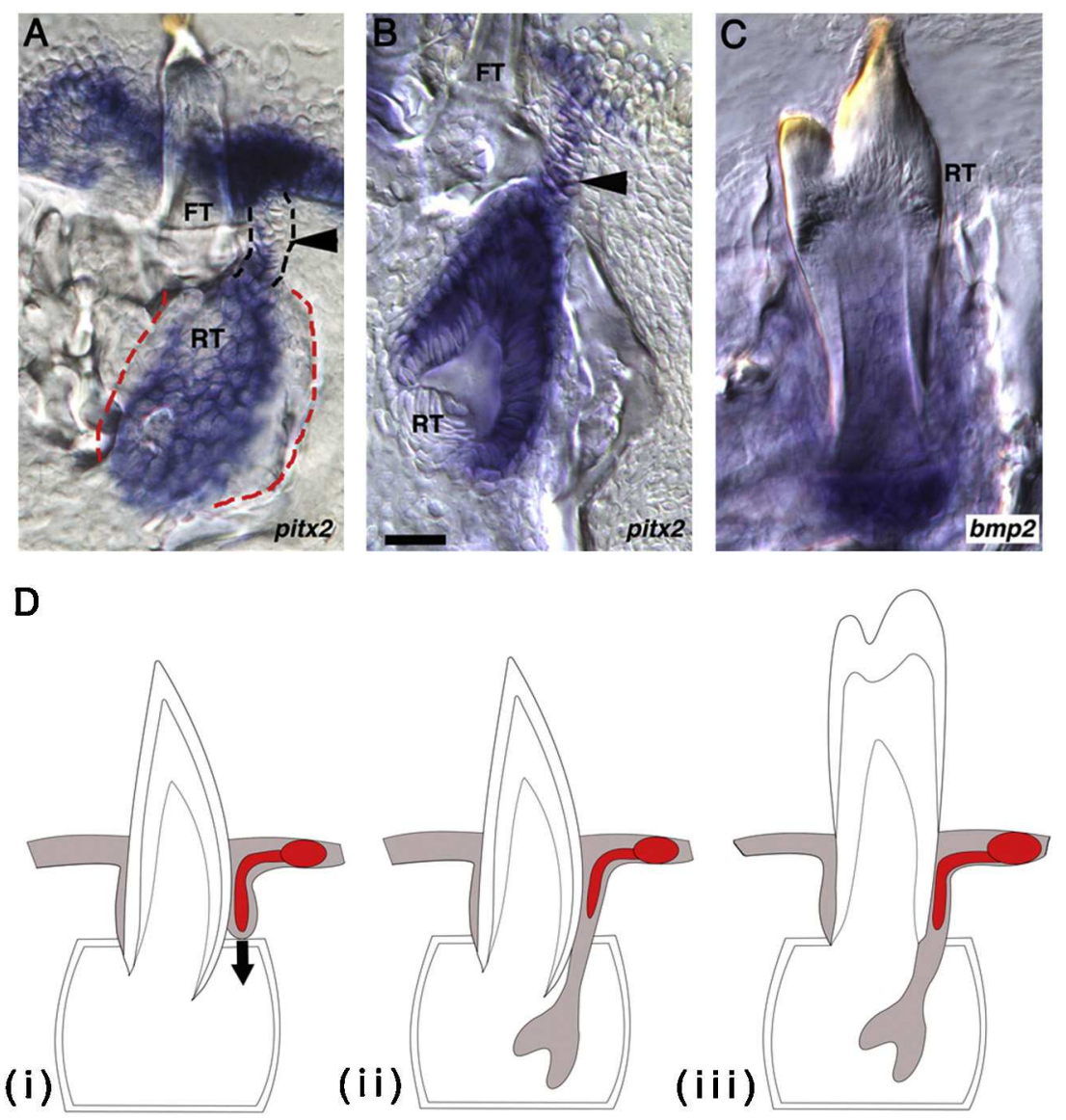

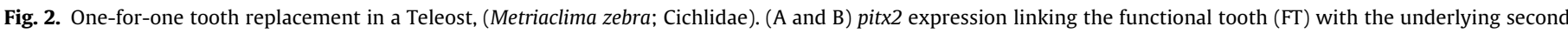

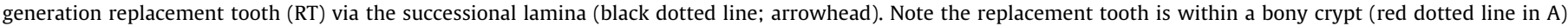

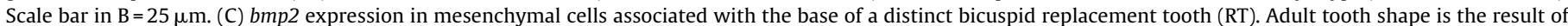

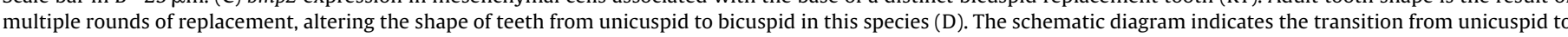

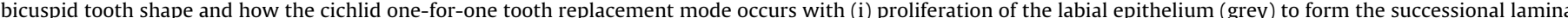

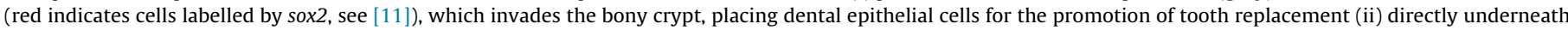
the predecessor. After rounds of replacement the adult tooth shape is generated (iii). 

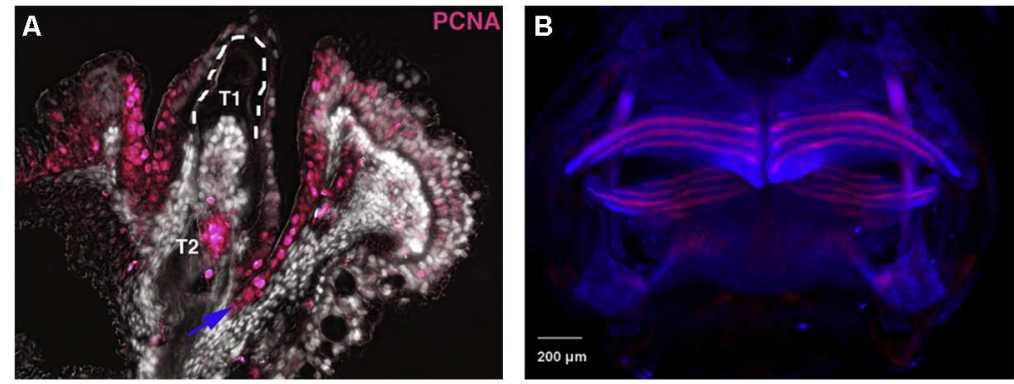

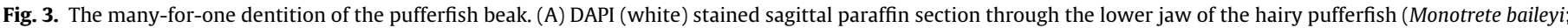

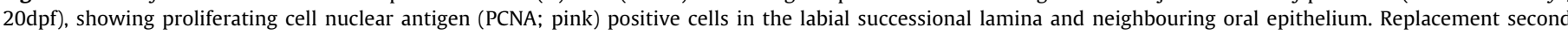

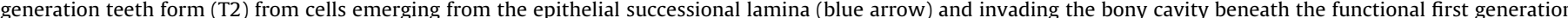

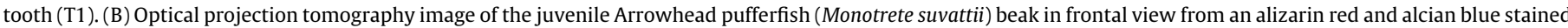
and cleared specimen, showing the pink fluorescent bands of stacked replacement dentine forming the beak. Scale bar $=200 \mu \mathrm{m}$.

In true toads (bufonids) the adults do not posses teeth, while in pipids and other frogs teeth are restricted to the upper jaw, with the exception of some hylids (tree frogs) [6,40]. Amphibian teeth are either pleurodont, where the functional tooth is attached on one side to the jaw bone, or in some cases acrodont, where the teeth are completely fused to the jaw, as seen in teleosts. Both situations of attachment can be observed in one animal, for example, in the Caudata and Gymnophiona the palatal teeth are acrodont, while the rest of the dentition are pleurodont [38]. These animals, therefore, present an excellent model to assess whether the type of tooth attachment impinges on the mode and rate of replacement.

In the few toothed amphibian species that have been studied a dental lamina has been observed extending on the lingual side of the functional tooth from which the next tooth develops [38,40-42]. The dental lamina is continuous with the oral epithelium and appears at a slight distance from the functional tooth, which was proposed to have detached from the lamina during calcification stages [42]. The successional tooth however appears to be connected both to the dental lamina and to its predecessor, indicating that the break with the lamina is not complete. Interestingly, the first generation of teeth are not always displaced by the eruption of the second generation, their retention creating two rows of teeth on the upper and lower jaws of young larvae [38]. Similar to tooth replacement in fish, replacement rates in amphibians often proceed at a greater speed in embryonic and juvenile stages compared to adults.

The speed of replacement of teeth in some amphibians has been shown to be directed by hormone levels. For example in Pleurodeles waltl if the level of thyroid hormone is inhibited teeth are replaced more slowly [43].

\subsubsection{Reptiles}

Reptiles can be divided into the Lepidosauria (Squamata and Rhynchocephalia), Crocodilia and the Chelonia (Testudines), with all extant Chelonia being edentate [6,15]. The Lepidosauria and Crocodilia are all toothed and are generally polyphyodont. An exception to this rule is the acrodonta clade (agamids and chameleons) from the Squamata, where a single generation of teeth are physically fused to the bone and are never replaced [44]. An acrodont dentition is also observed in the single surviving species of Rynchocephalia (Sphenodon), where only a reduced tooth replacement, restricted to specific parts of the jaw, has been described [45]. In contrast, in polyphyodont reptile species the teeth are generally attached to the jaw bones by either a pleurodont or thecodont attachment. A thecodont attachment is observed in the crocodilia, and is characterised by having the tooth sitting in a socket attached to the bone via a fibrous connection [46]. In the acrodonta there appears to be a trade-off between the advantage of a firmly attached tooth and the ability to replace the teeth. In acrodonta such as the veiled chameleon, the teeth fuse not only to the jaw bones but also to each other, and when worn down during mastication form a sharp serrated pad, allowing the cutting of vegetation (Fig. 4). Comparing the developmental difference between reptiles that regenerate their teeth and those that do not provides an excellent opportunity to study the mechanisms responsible for the control of tooth number.

Similar to the chondrichthyan and amphibian species studied, the replacing series of tooth germs in polyphyodont squamates are united by a permanent dental lamina linking the developing teeth in a chain to the functional dentition, and the oral surface $[10,12,47,48]$. At birth $3-4$ developing generations of teeth are found linked to the dental lamina, making a developmental series ready to replace the functional tooth. In fanged snakes this series of replacement teeth is even longer, with approximately eight teeth ready to place the fangs [49], similar to the number of replacement teeth observed in the chondrichthyans. In the crocodilia, only one developing replacement tooth is observed behind the functional tooth, and together with the dental lamina they form a family unit [46]. This smaller number of tooth germs developing along the dental lamina at any one time may relate to the speed of replacement. Crocodilians are thought to replace their teeth once a year [50], in contrast to squamata that have a much quicker turnover with replacement around 4 times a year [51]. The need for a series of developing tooth germs may therefore only be required in animals with higher turnovers. During development in the Nile crocodile the dental lamina extends out from the forming functional tooth and replacement tooth formation can be observed, mimicking the process in squamates [52]. However, at later stages in crocodilians the dental lamina appears to lose its connection to the oral surface and to the functional tooth it will replace, while still remaining connected longitudinally to the dental lamina along the jaw [46]. Thus connection between the dental lamina and the overlying oral epithelium does not appear necessary for its function in these animals. The end of the crocodilian dental lamina forms a bulge, which enlarges at the start of initiation of the next replacement tooth. The dental lamina then splits from this replacement tooth as it progresses to differentiation [46]. In the squamata and crocodilia, like the amphibia, the replacement teeth form on the lingual side of the functional tooth. This lining up of replacement teeth on the lingual side can be viewed clearly by microcT (Fig. 4). The exception to this rule is the inner row of teeth on the upper jaw of the snake, where the two dental laminas appear as mirror images of each other and the replacement teeth on the inner row form buccally rather than lingually [53]. A similar mirror image development of palatal teeth is also found in Sphenodon [45] 


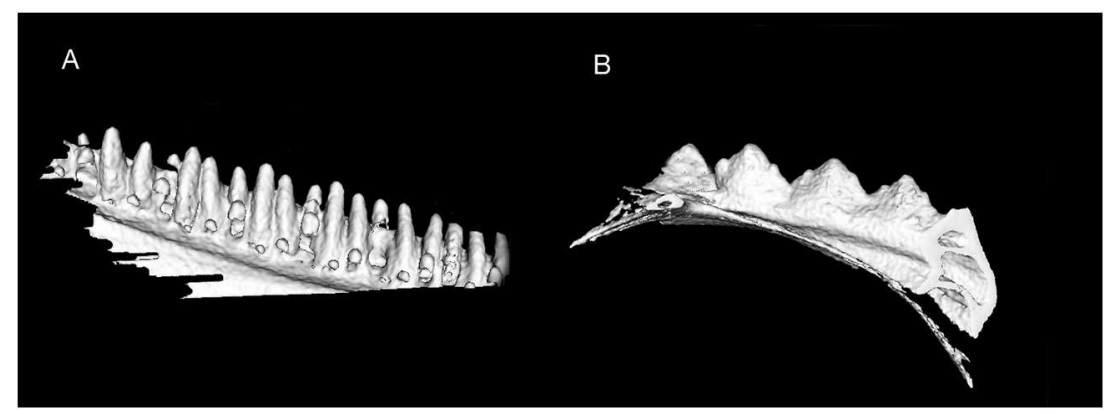

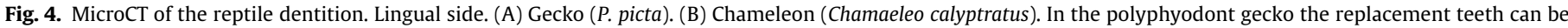

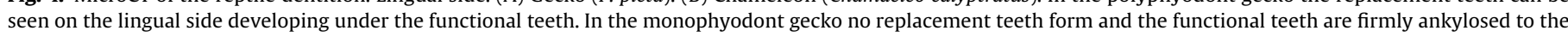
bone and to each other.

In most toothed reptiles a non-functional set of teeth is observed developing early on in the embryo, these teeth forming superficially on the oral surface rather than being associated with a dental lamina $[13,48,52,54]$. These non-functional tooth germs have been proposed to be remnants of a larval dentition, that became redundant with the extension of the embryonic period [52]. The first developing teeth are not physically connected to the functional teeth and are not part of a replacement series, however these first rudimentary tooth germs develop in positions near to where the dental lamina is due to develop and may play a role in patterning of the later functional dentition [48]. All functional teeth, however, develop from the dental lamina. The dental lamina is therefore not required for tooth development, but maybe essential for the controlled replacement of teeth.

As in fish and amphibians, in squamates the deepest part of the dental lamina ends in a bulge known as the successional lamina. This bulge has been found during development in all toothed reptile species examined, even those with only one set of functional teeth $[44,46,55]$. The squamate successional lamina is a region of high proliferation and low apoptosis (programmed cell death) [47,56]. Fate mapping of the successional lamina in the snake has shown that the cells in the successional lamina contribute both to the new generations of teeth and are retained at the tip of the lamina [10]. In species that only have one set of teeth the successional lamina forms but stops proliferating, losing its bulge shape. At the same time apoptosis is upregulated at the end of the lamina [44,55,57]. Interestingly loss of the successional lamina, and therefore the ability to make a second generation of teeth, is associated with the timing of fusion of the functional tooth with the surrounding bone [44]. The signal for degradation of the lamina may therefore come from the functional tooth and bone. To test this it would be interesting to see whether successional laminas will form a second generation if isolated from the functional tooth. In the gecko it has been shown that the dental lamina, houses label retaining cells, identified by pulse-chase BrdU experiments, suggesting that this is the site for epithelial stem cells [12]. These putative stem cells may therefore provide the machinery to generate replacement teeth. A similar population of label retaining cells has been described at the distal end of the dental lamina at the pre-initiation stage in the alligator [46]. The label retaining cells were found to remain at fairly steady levels during the process of tooth replacement, while a population of transit amplifying cells were found to peak at late initiation and then reduced in numbers as the dental lamina bulge grew [46]. Interestingly, extraction of a functional tooth in the alligator led to stimulation of the dental lamina to initiate a new tooth cycle, however, in sharks tooth loss does not alter the set rate of production of replacement teeth $[23,46]$. Whether tooth loss and damage impact on the timing of tooth replacement, therefore, appears to vary between species and may be influenced by the stage of development of the replacement tooth.

\subsection{Mammals}

Mammals, in contrast to the polyphyodont vertebrate species previously mentioned, are generally restricted to two generations of teeth (Diphyodont). This reduction in replacement appears correlated with the requirement of complex occlusion for efficient food processing $[22,58]$. The functional mammalian teeth sit in a socket in the jaw (thecodont attachment), a situation similar to Crocodilians but this appears to be a case of convergent evolution [59]. Two functional generations appears to be the primitive therian pattern, with replacement of teeth at the incisor, canine and premolar positions, while the adult molars are not replaced.

Some mammals, however, only have one set of functional teeth, and are therefore monophyodont. Some monophyodont mammals display hypselodonty (continuously growing teeth). In rabbits and guinea pigs both the molars and incisors continuously grow, while in rats and mice this ability is restricted to the incisors. In other monophyodont mammals, the teeth have very high crowns protecting the tooth pulp during erosion (hypsodont teeth). In some monophyodont mammals (shrews, tooth whales, some bats, some moles), tooth replacement does occur but the first set of teeth are non-functional and abort during development, so that the animal only has one set of functional teeth. In the shrew this loss of the first set of tooth germs appears to involve apoptosis [60]. Repression of the development of the shrew primary (deciduous) dentition has been suggested to be driven by premature initiation and development of the permanent dentition [61]. The relative timing of replacement can therefore have a big impact on the numbers of functional tooth generations.

In diphyodont species a dental lamina connects the developing functional tooth to its replacement tooth on the lingual side of the jaw, similar to the situation in the other toothed vertebrates [62]. Unlike in polyphyodont chondrichythans and squamates, however, this lamina extending from the replacement tooth germ disappears and does not give rise to an additional replacement tooth $[63,64]$. This part of the lamina has been proposed to contain the dental epithelial stem cells and this breakdown may result in loss of the cells that would normally make the next tooth, or alternatively break down could be a consequence of loss of odontogenic potential in this region. In the mini-pig the loss of the dental lamina appears to involve a mix of apoptosis and transformation of the epithelial lamina cells to a mesenchymal fate [57]. Failure for the lamina to break down completely has been proposed to be the cause of epithelial pearls, which can lead to cysts and tumours $[63,65]$.

Permanent molars develop behind the deciduous dentition and are not replaced. As such molars are part of the primary dentition. A single molar placode however can generate a number of molars that appear to bud off from one another. This process is very similar to that of replacement tooth development, but instead of vertical development, the molars develop horizontally within the jaw and 
function together at the same time, a process that has been called serial addition [14]. In serial addition the molars are connected by a dental lamina like structure that is attached to the oral epithelium and develop in a series. In almost all eutherian mammals three molars develop from the molar placode. The first molar (M1) followed by the M2 and then the M3, after which point the ability to form subsequent molars stops. In marsupials four molars form from the molar placode. In some animals with long life spans, such as elephants, the development of the more posterior molars is delayed so that when a molar wears down the next molar in sequence erupts to take over the grinding function and the more anterior worn tooth is lost. In a few mammals this process of serial addition does not stop and molar teeth keep forming at the back of the mouth. This can be seen in the rock wallaby (Petrogale concinna), three manatee species and the African mole rat (Heliophobius argenteocinereus). Therefore only 5 species from the 5500 known mammalian species have evolved this ability to continuous replace their teeth, which has occurred convergently in the three groups. These additional molars act as replacement teeth, moving forward in the jaw as the more anterior molars are lost [66], and are thought to be an adaption to a highly abrasive diet. What limits the number of molars in most mammal species is an interesting question. An inhibitory cascade model has been proposed involving a balance of activator and inhibitor signalling. In support of this model, removal of the murine M1 from the developing M2 placode in culture has been shown to lead to the formation of a 4th molar (M4) [67]. A comparison of the dynamics of the dental lamina in species with and without continuous replacement may also provide some answers to how molar number is regulated.

\section{The dental lamina as a conserved feature of replacement dentitions}

The source of epithelial cells necessary for replacing teeth, in most toothed vertebrates, appears to be the dental lamina $[10,12,14,28,30,33,46,57,62]$. The early odontogenic band provides genetic cues that support a dental fate and the patterning of tooth units from these epithelial cells. Cells of the dental lamina are likely to be essential for the capacity to replace the entire dentition [30] and without the maintenance of these specialised cells the dentition would not replenish and in some cases could be lost, as observed in many mammals. The dental lamina can be structurally diverse among vertebrates - even within each clade of vertebrates the mode of tooth replacement can show variation (Fig. 5), however the genes that are expressed during tooth replacement are conserved among all vertebrates studied.

\section{The conserved genetic basis for tooth replacement}

The dentition is a replacement module. However, as discussed, there is a vast diversity of dental phenotypes and replacement capacity among the toothed vertebrates, where some have limited replacement ability and others have a continuous and unlimited supply. Key questions based on these observations are what governs the continued maintenance of the dental replacement system in lower vertebrates, and what factors induce the break down of the regenerative capacity thereby limiting the production of tooth replacements observed in mammals. More recently research has uncovered the basic developmental genetics and functional mechanisms of tooth replacement in a diverse selection of animals (i.e. reptiles and fishes) although a complete set of genes and functional 'gene network for replacement' is still very much a future priority. Many genes expressed during the process of tooth replacement are highly conserved from the emergence of the first generation and appear to be essential for epithelial maintenance necessary for the cyclical regeneration of the dental system. Recent dental research has identified novel markers of tooth replacement and renewal that appear to be regulators of other regenerative systems such as hair, feather and wound healing $[4,12,14,46,68]$. In this age of stem cell and regenerative biological research many studies are based on the knowledge of adult stem cell populations following the principle that many of the same genes are involved in maintenance and regulation of stem cells. This is a common thread uniting many regenerative systems regardless of how divergent they appear, including the dentition.

One such example is Sox2 (Fig. 6), which plays a critical role in maintenance of stem cells in multiple tissues, including the brain, stomach, lens and testes $[69,70]$. Sox2 is also an important
A

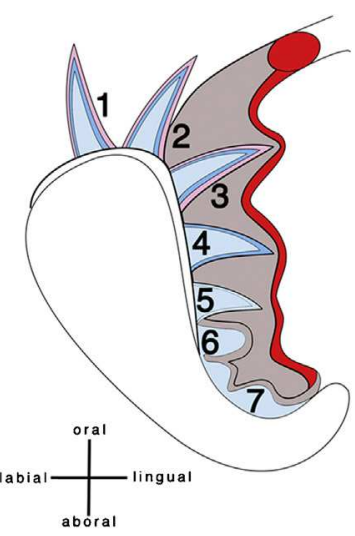

B

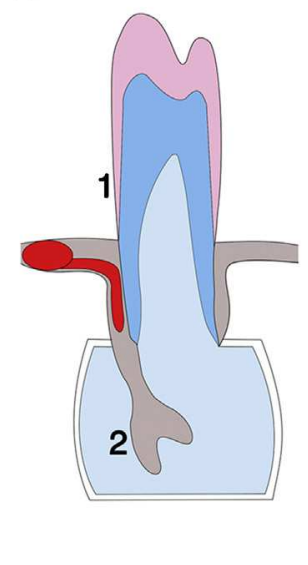

C

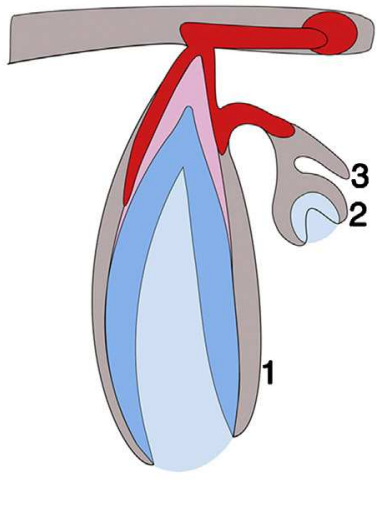

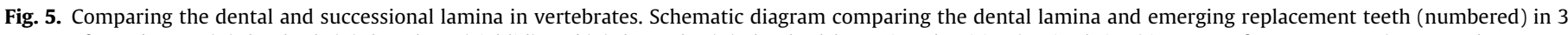

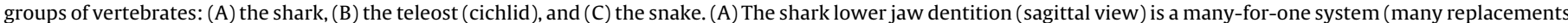

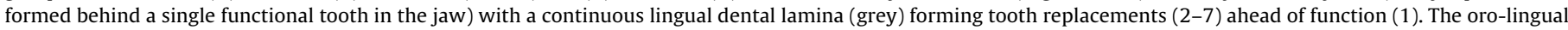

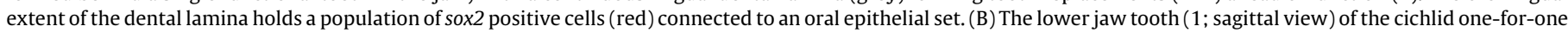

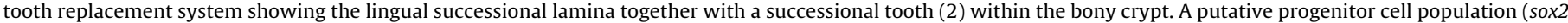

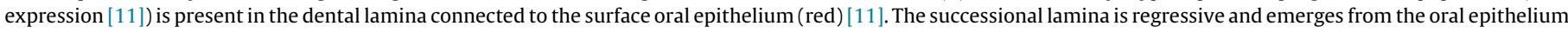

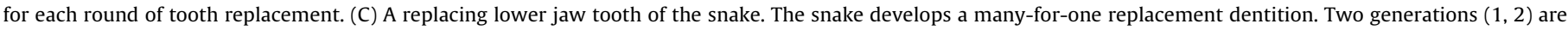

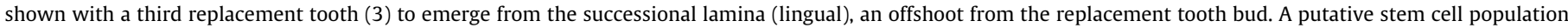

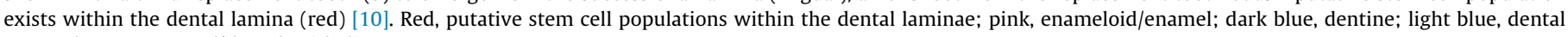
mesenchyme; grey oral/dental epithelium. 

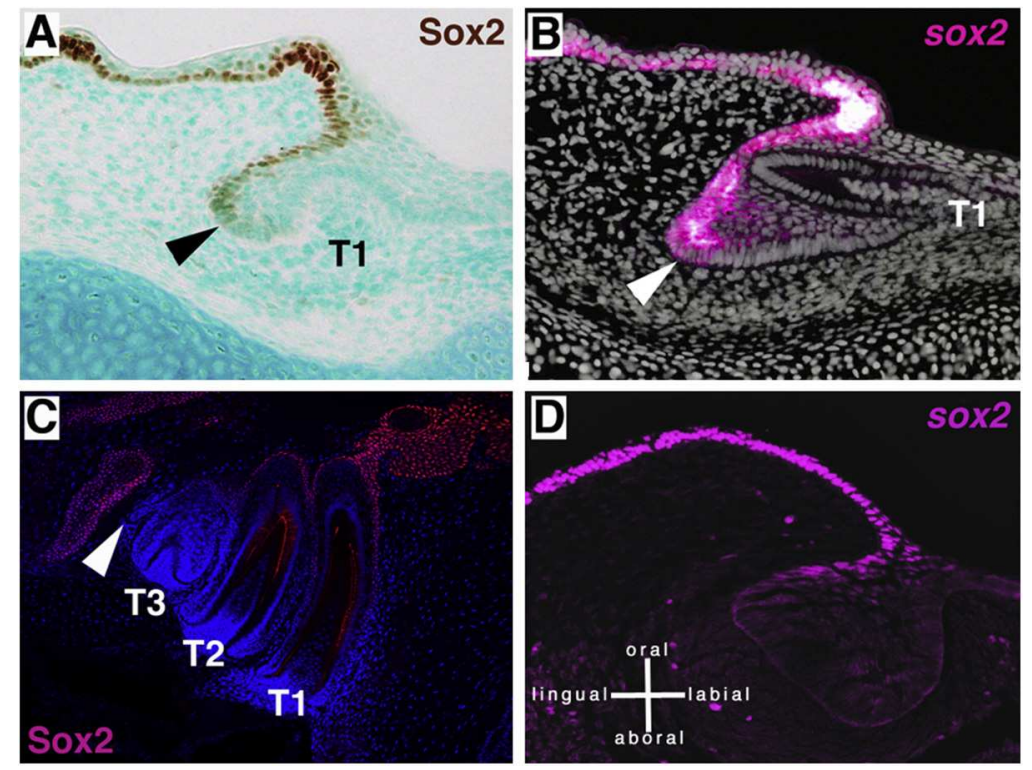

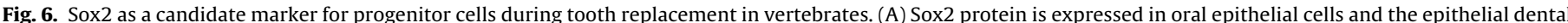

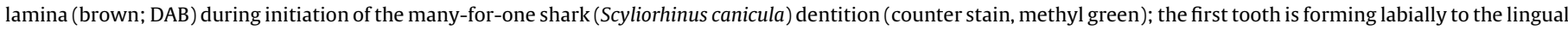

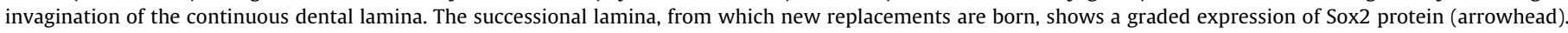

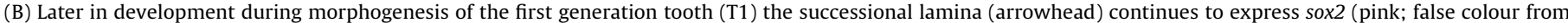

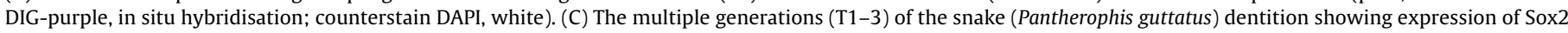

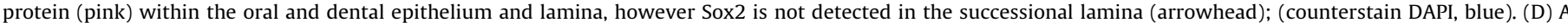

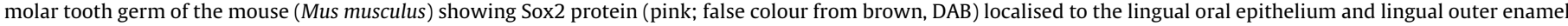
epithelial cells of the tooth.

co-inducer of iPS (induced pluripotent stem cells) cells [71]. In the mouse incisor Sox2 is localised to the labial cervical loop, a known site for epithelial stem cells for the continuously growing incisor [4]. In regenerating dentitions, Sox2 expression has been proposed to mark epithelial competence to generate teeth in both mammals and reptiles [14]. Initially Sox2 is expressed in the odontogenic band and the lingual dental epithelium, even in the monophyodont mouse. This lingual expression remains throughout development, highlighting the difference between the epithelium on the lingual and labial sides of the tooth. Expression of putative stem cell markers on the lingual side of the developing tooth may explain why the dental lamina is always found on the lingual side of the tooth germ. In diphyodont mammals, such as the ferret, Sox2 lines the lingual side of the dental lamina but is excluded from the very tip [14]. A similar expression has been shown in a variety of polyphyodont reptiles (gecko, alligator, python and corn snake $[10,14]$ (Fig. 6). In the corn snake the expression of sox2 is complementary to high levels of Wnt signalling as indicated by Lef1 expression, indicating compartmentalisation of the dental lamina [10]. Bmp and Shh signalling has been proposed to play a role in setting up this pattern of Wnt in the dental lamina [13]. Overexpression of Wnt signalling in the mouse dental epithelium leads to the production of numerous small teeth from the molar placode [72], while overexpression throughout the dental lamina, leads to a restriction in Sox2 expression and a loss of the usual regulated sequence of tooth replacement in snakes [10]. Regulation of Wnt signalling therefore appears important in mammals and reptiles. Sox 2 is also linked to the successional development of molars in the mouse, with Sox2+ve cells of the 1 st molar contributing to the 2 nd and 3rd molars [4,14], linking the genetic regulation of dental replacement and serial addition. A number of stem cells markers (Dkk3, Lgfbp5, Lgr5) have been identified in the gecko dental lamina [12], supporting the dental lamina as a source of stem cells for dental regeneration. Sox2/sox2 is also associated with the lingual proliferation of the odontogenic band and the continuous dental lamina in the shark (Scyliorhinus canicula; Figs. 1, 5 and 6) and the teleost fish (i.e. cichlids; [11]), thus is seems clear that Sox2 is a conserved regulator of tooth replacement throughout the vertebrates, spanning 500 million years of tooth replacement (Fig. 6). Although the mode of tooth replacement and the cellular organisation may vary among vertebrates and within groups of vertebrates, the process of tooth replacement, like the production of tooth units, remains well conserved. Therefore the conserved mechanism and genetics of tooth replacement suggest that information gleaned from any vertebrate will be important to our understanding of the evolution of the dental system.

\section{Conclusions}

Many self-regenerating or replacement systems share a common set of functional genes and cellular dynamics - in this respect the dentition is not unique and many factors utilised in tooth development and replacement are also involved in ectodermal unit development and regeneration, such as in the hair [73,74]. Our view of the dental paradox suggests that this conserved system with common genetic and cellular mechanisms that are deep rooted in evolutionary time must have the capacity to allow great shifts in the developmental and therefore morphological diversity of the dentition. This diversity can and will persist, because it is related to adaptation of function in the environment. Dental diversity could exist or present itself more so in species/groups with a continuous tooth replacement system where the vast number of replicate structures and the senescence of the system (over time) could produce ontogenetic shifts that alter the product that confers an adaptive advantage within the community or novelty. This evolutionary context presents the dentition as a unique system for the study of morphological and developmental novelty $[75,76]$. Take the puffefish for example (and other members of the Tetraodontiformes) [37], what governs the changes during the formation of the second-generation dentition, the replacement teeth, that begin developmental and structural shifts towards the unique beak-like jaw and tooth module? This modification of conserved developmental mechanisms has led to the generation of dental novelty. 
The ability of groups of fish to alter a seemingly 'standard' and conserved dentition into a unique morphology during the process of increasing replacements is remarkable and novel among vertebrates. The regenerative capacity of the vertebrate dentition has played a significant role in the diversity of vertebrates. Consequently, the modulation of the dental replacement toolkit has allowed other vertebrates to either alter their dentition or replace the dentition with other modified structures, e.g. keratin-based units that aid the acquisition of food. The dentition and its replacement system are essential to an organism's success and it seems key to the evolution and alteration of the integrated tooth-jaw module.

\section{Acknowledgements}

We thank Marcia Gaete for her review of the manuscript and images of Sox2 in the snake. We also thank Liam Rasch for images of PCNA in the catshark and pufferfish and Sox2 in the catshark. We are grateful to Alasdair Edgar and Moya Smith for the optical projection tomography image of the pufferfish beak and Ralf Britz for Pufferfish (M. baileyi) embryos.

\section{References}

[1] Wang XP, Suomalainen M, Felszeghy S, Zelarayan LC, Alonso MT, Plikus MV, et al. An integrated gene regulatory network controls stem cell proliferation in teeth. PLoS Biol 2007;5:e159.

[2] Thesleff I, Tummers M. Tooth organogenesis and regeneration. In: Community TSCR, editor. StemBook. 2010/07/09. Harvard Stem Cell Institute; 2008.

[3] Harada H, Kettunen P, Jung HS, Mustonen T, Wang YA, Thesleff I. Localization of putative stem cells in dental epithelium and their association with Notch and FGF signaling. J Cell Biol 1999;147:105-20.

[4] Juuri E, Saito K, Ahtiainen L, Seidel K, Tummers M, Hochedlinger K, et al. Sox2+ stem cells contribute to all epithelial lineages of the tooth via Sfrp5+ progenitors. Dev Cell 2012;23:317-28.

[5] Chen Y, Zhang Y, Jiang TX, Barlow AJ, St Amand TR, Hu Y, et al. Conservation of early odontogenic signaling pathways in Aves. Proc Natl Acad Sci U S A 2000:97:10044-9.

[6] Davit-Beal T, Tucker AS, Sire JY. Loss of teeth and enamel in tetrapods: fossil record, genetic data and morphological adaptations. J Anat 2009;214: 477-501.

[7] Kollar EJ, Fisher C. Tooth induction in chick epithelium: expression of quiescent genes for enamel synthesis. Science 1980;207:993-5.

[8] Stock DW. Zebrafish dentition in comparative context. J Exp Zool B: Mol Dev Evol 2007:308:523-49.

[9] Stock DW, Jackman WR, Trapani J. Developmental genetic mechanisms of evolutionary tooth loss in cypriniform fishes. Development 2006;133: 3127-37.

[10] Gaete M, Tucker AS. Organized emergence of multiple-generations of teeth in snakes is dysregulated by activation of wnt/beta-catenin signalling. PLoS ONE 2013;8:e74484

[11] Fraser GJ, Bloomquist RF, Streelman JT. Common developmental pathways link tooth shape to regeneration. Dev Biol 2013;377:399-414.

[12] Handrigan GR, Leung KJ, Richman JM. Identification of putative dental epithelial stem cells in a lizard with life-long tooth replacement. Development 2010:137:3545-9.

[13] Handrigan GR, Richman JM. A network of Wnt, hedgehog and BMP signaling pathways regulates tooth replacement in snakes. Dev Biol 2010;348:130-41.

[14] Juuri E, Jussila M, Seidel K, Holmes S, Wu P, Richman J, et al. Sox2 marks epithelial competence to generate teeth in mammals and reptiles. Development 2013; $140: 1424-32$.

[15] Tokita M, Chaeychomsri W, Siruntawineti J. Developmental basis of toothlessness in turtles: insight into convergent evolution of vertebrate morphology. Evolution 2013;67:260-73.

[16] Grande L, Bemis WE. Interrelationships of Acipenseriformes with comments on “Chondrostei". In: Stiassny M, Parenti L, Johnson D, editors. Interrelationships of fishes. San Francisco: Academic Press; 1996. p. 85-115.

[17] Fraser GJ, Hulsey CD, Bloomquist RF, Uyesugi K, Manley NR, Streelman JT. An ancient gene network is co-opted for teeth on old and new jaws. PLoS Biol 2009:7:e31.

[18] Donoghue PC, Sansom IJ, Downs JP. Early evolution of vertebrate skeletal tissues and cellular interactions, and the canalization of skeletal development. J Exp Zool B: Mol Dev Evol 2006;306:278-94

[19] Donoghue PCJ. Evolution of development of vertebrate teeth and scales: unravelling concepts, regulatory theories and homologies. Paleobiology 2002;28:474-507

[20] Smith MM, Coates MI. Evolutionary origins of the vertebrate dentition: phylogenetic patterns and developmental evolution. Eur J Oral Sci 1998;106(Suppl. 1):482-500.
[21] Smith MM, Coates MI. Evolutionary origins of teeth and jaws: developmental models and phylogenetic patterns. In: Teaford MF, Smith MM, Ferguson MWJ, editors. Development, function and evolution of teeth. Cambridge: Cambridge University Press; 2000, p. 133-51.

[22] Jernvall J, Thesleff I. Tooth shape formation and tooth renewal: evolving with the same signals. Development 2012;139:3487-97.

[23] Reif W-E, McGill D, Motta P. Tooth replacement rates of the sharks Triakis semifasciata and Ginglymostoma cirratum. Zoll Jb Anat Bd 1978;99:151-6.

[24] Luer CA, Blum PC, Gilbert PW. Rate of tooth replacement in the nurse shark, Ginglymostoma cirratum. Copeia 1990;1990:182-91.

[25] Jackman WR, Draper BW, Stock DW. Fgf signaling is required for zebrafish tooth development. Dev Biol 2004;274:139-57.

[26] Fraser GJ, Bloomquist RF, Streelman JT. A periodic pattern generator for dental diversity. BMC Biol 2008;6:32.

[27] Fraser GJ, Graham A, Smith MM. Conserved deployment of genes during odontogenesis across osteichthyans. Proc R Soc Lond B: Biol Sci 2004;271:2311-7.

[28] Fraser GJ, Graham A, Smith MM. Developmental and evolutionary origins of the vertebrate dentition: molecular controls for spatio-temporal organisation of tooth sites in osteichthyans. J Exp Zool B: Mol Dev Evol 2006;306:183-203.

[29] Smith MM. Vertebrate dentitions at the origin of jaws: when and how pattern evolved. Evol Dev 2003;5:394-413.

[30] Smith MM, Fraser GJ, Mitsiadis TA. Dental lamina as source of odontogenic stem cells: evolutionary origins and developmental control of tooth generation in gnathostomes. J Exp Zool B: Mol Dev Evol 2009;312B:260-80.

[31] Smith MM, Fraser GJ, Chaplin N, Hobbs C, Graham A. Reiterative pattern of sonic hedgehog expression in the catshark dentition reveals a phylogenetic template for jawed vertebrates. Proc Biol Sci 2009;276:1225-33.

[32] Reif WE. Development of dentition and dermal skeleton in embryonic Scyliorhinus canicula. J Morphol 1980;166:275-88.

[33] Fraser GJ, Berkovitz BK, Graham A, Smith MM. Gene deployment for tooth replacement in the rainbow trout (Oncorhynchus mykiss): a developmental model for evolution of the osteichthyan dentition. Evol Dev 2006:8:446-57.

[34] Fraser GJ, Bloomquist RF, Streelman JT. Common developmental pathways link tooth shape to regeneration. Dev Biol 2013;377(2):399-414.

[35] Tuisku F, Hildebrand C. Evidence for a neural influence on tooth germ generation in a polyphyodont species. Dev Biol 1994;165:1-9.

[36] Streelman JT, Webb JF, Albertson RC, Kocher TD. The cusp of evolution and development: a model of cichlid tooth shape diversity. Evol Dev 2003;5:600-8.

[37] Fraser GJ, Britz R, Hall A, Johanson Z, Smith MM. Replacing the firstgeneration dentition in pufferfish with a unique beak. Proc Natl Acad Sci U S A 2012;109:8179-84.

[38] Davit-Beal T, Allizard F, Sire JY. Morphological variations in a tooth family through ontogeny in Pleurodeles waltl (Lissamphibia, Caudata). J Morphol 2006;267:1048-65.

[39] Shaw JP. The time scale of tooth development and replacement in Xenopus laevis. J Anat 1979:129:323-42.

[40] Goin CJ, Hester M. Studies on the development, succession and replacement of teeth in the frog Hyla cinerea. J Morphol 1961;109:279-87.

[41] Davit-Beal T, Chisaka H, Delgado S, Sire JY. Amphibian teeth: current knowledge, unanswered questions, and some directions for future research. Biol Rev Camb Philos Soc 2007;82:49-81.

[42] Gillette R. The dynamics of continuous succession of teeth in the frog (Rana pipiens). Am J Anat 1955:96:1-36

[43] Chibon P, Dournon C. Effects of thyroid hormone on cell proliferation in the amphibian larva (author's transl). Annales d'endocrinologie 1974;35:296-7.

[44] Buchtová M, Zahradnicek O, Balkova S, Tucker AS. Odontogenesis in the veiled chameleon (Chamaeleo calyptratus). Arch Oral Biol 2013;58:118-33.

[45] Harrison HS. Development and succession of the teeth in Hatteria punctata. Quart J Microsc Sci 1901;44:161-213.

[46] Wu P, Wu X, Jiang TX, Elsey RM, Temple BL, Divers SJ, et al. Specialized stem cell niche enables repetitive renewal of alligator teeth. Proc Natl Acad Sci U S A 2013;110:E2009-18

[47] Buchtova M, Handrigan GR, Tucker AS, Lozanoff S, Town L, Fu K, et al. Initiation and patterning of the snake dentition are dependent on Sonic hedgehog signaling. Dev Biol 2008;319:132-45.

[48] Zahradnicek O, Horacek I, Tucker AS. Tooth development in a model reptile: functional and null generation teeth in the gecko Paroedura picta. J Anat 2012;221:195-208.

[49] Zahradnicek O, Horacek I, Tucker AS. Viperous fangs: development and evolution of the venom canal. Mech Dev 2008;125:786-96.

[50] Edmund AG. Sequence and rate of tooth replacement in the crocodilia, vol. 56 University of Toronto: Royal Ontario Museum-Life Science Division; 1962. p. $7-42$.

[51] Edmund AG. Tooth replacement phenomena in the lower vertebrates. Contrib Life Sci Div R Ontario Museum 1960;52:1-42.

[52] Sire JY, Davit-Beal T, Delgado S, Van Der Heyden C, Huysseune A. Firstgeneration teeth in nonmammalian lineages: evidence for a conserved ancestral character. Microsc Res Tech 2002:59:408-34.

[53] Buchtová M, Boughner JC, Fu K, Diewert VM, Richman JM. Embryonic development of Python sebae. II. Craniofacial microscopic anatomy, cell proliferation and apoptosis. Zoology (Jena) 2007:110:231-51.

[54] Westergaard B, Ferguson MWJ. Development of the dentition in Alligator mississipiensis. Early embryonic development in the lower jaw. J Zool Anat 1986;210:575-97.

[55] Richman JM, Handrigan GR. Reptilian tooth development. Genesis 2011;49:247-60 
[56] Handrigan GR, Richman JM. Autocrine and paracrine Shh signaling are necessary for tooth morphogenesis, but not tooth replacement in snakes and lizards (Squamata). Dev Biol 2010;337:171-86.

[57] Buchtova M, Stembirek J, Glocova K, Matalova E, Tucker AS. Early regression of the dental lamina underlies the development of diphyodont dentitions. J Dent Res 2012;91:491-8.

[58] Kielan-Jaworowska Z, Cifelli RL, Luo ZX. Mammals from the age of dinosaurs: origins, evolution, and structure. New York: Columbia University Press; 2004.

[59] McIntosh JE, Anderton X, Flores-De-Jacoby L, Carlson DS, Shuler CF, Diekwisch TG. Caiman periodontium as an intermediate between basal vertebrate ankylosis-type attachment and mammalian true periodontium. Microsc Res Tech 2002;59:449-59.

[60] Sasaki C, Sato T, Kozawa Y. Apoptosis in regressive deciduous tooth germs of Suncus murinus evaluated by the TUNEL method and electron microscopy. Arch Oral Biol 2001;46:649-60.

[61] Jarvinen E, Valimaki K, Pummila M, Thesleff I, Jernvall J. The taming of the shrew milk teeth. Evol Dev 2008;10:477-86

[62] Jarvinen E, Tummers M, Thesleff I. The role of the dental lamina in mammalian tooth replacement. J Exp Zool B: Mol Dev Evol 2009;312B:281-91.

[63] Moskow BS, Bloom A. Embryogenesis of the gingival cyst. J Clin Periodontol 1983:10:119-30

[64] Stembirek J, Buchtová M, Kral T, Matalova E, Lozanoff S, Misek I. Early morphogenesis of heterodont dentition in minipigs. Eur J Oral Sci 2010;118:547-58.

[65] Eversole LR. Malignant epithelial odontogenic tumors. Semin Diagn Pathol 1999:16:317-24

[66] Rodrigues HG, Marangoni P, Sumbera R, Tafforeau P, Wendelen W, Viriot L. Continuous dental replacement in a hyper-chisel tooth digging rodent. Proc Natl Acad Sci U S A 2011;108:17355-9.
[67] Kavanagh KD, Evans AR, Jernvall J. Predicting evolutionary patterns of mammalian teeth from development. Nature 2007;449:427-32.

[68] Biehs B, Hu JK, Strauli NB, Sangiorgi E, Jung H, Heber RP, et al. BMI1 represses Ink4a/Arf and Hox genes to regulate stem cells in the rodent incisor. Nat Cell Biol 2013; 15:846-52.

[69] Arnold K, Sarkar A, Yram MA, Polo JM, Bronson R, Sengupta S, et al. Sox2(+) adult stem and progenitor cells are important for tissue regeneration and survival of mice. Cell Stem Cell 2011;9:317-29.

[70] Suh H, Consiglio A, Ray J, Sawai T, D’Amour KA, Gage FH. In vivo fate analysis reveals the multipotent and self-renewal capacities of Sox $2+$ neural stem cells in the adult hippocampus. Cell Stem Cell 2007;1:515-28.

[71] Takahashi K, Yamanaka S. Induction of pluripotent stem cells from mouse embryonic and adult fibroblast cultures by defined factors. Cel 2006;126:663-76.

[72] Jarvinen E, Salazar-Ciudad I, Birchmeier W, Taketo MM, Jernvall J, Thesleff I. Continuous tooth generation in mouse is induced by activated epithelial Wnt/beta-catenin signaling. Proc Natl Acad Sci U S A 2006;103:18627-32.

[73] Plikus MV, Baker RE, Chen CC, Fare C, de la Cruz D, Andl T, et al. Self-organizing and stochastic behaviors during the regeneration of hair stem cells. Science 2011;332:586-9.

[74] Plikus MV, Mayer JA, de la Cruz D, Baker RE, Maini PK, Maxson R, et al. Cyclic dermal BMP signalling regulates stem cell activation during hair regeneration. Nature 2008;451:340-4.

[75] Hallgrimsson B, Jamniczky HA, Young NM, Rolian C, Schmidt-Ott U, Marcucio RS. The generation of variation and the developmental basis for evolutionary novelty. J Exp Zool B: Mol Dev Evol 2012;318:501-17.

[76] Raff RA. The shape of life: genes, development, and the evolution of animal form. Chicago, IL, USA: University of Chicago Press; 1996. 